\title{
La ideología de género y la consolidación de la nueva derecha en Baja California, México*
}

\author{
The gender ideology \\ and the consolidation of the new right \\ in Baja California, Mexico
}

\author{
ARELI VELOZ**
}

\begin{abstract}
This article from a qualitative analysis perspective, explains the actions of the middle and upper classes to shape and strengthen, at the local level, the new right. I analyze the historical context and the social unrest that these groups attribute to family crises and traditional sexualities, which redefine their critical discourses towards "gender ideology". The originality of this article is that it shows how political discourses underlie a creationist vision of life where women are seen as responsible for the parturition of the nation's future citizens. It is concluded that the strategies of the new right, implicitly, consist on defending and strengthening the patriarchy, which they see as imperiled by feminism.
\end{abstract}

Key words: Gender ideology, new right, feminism, sexualities, social classes

\section{Resumen}

Este artículo, desde una perspectiva de análisis cualitativo, tiene el objetivo de analizar las acciones que las clases medias y altas llevan a cabo para conformar $y$ fortalecer, en el plano local, a la nueva derecha. Se examina el contexto histórico y los malestares sociales que esos grupos atribuyen a las crisis de la familia y las sexualidades tradicionales, mismos que redefinen sus discursos críticos hacia la ideología de género. La originalidad de este artículo reside en que muestra cómo los discursos políticos subyacen en una visión creacionista de la vida, donde las mujeres son vistas como las responsables de reproducir a los futuros ciudadanos de la nación. Se concluye que las estrategias de la nueva derecha, implícitamente, consisten en defendery fortalecer al patriarcado, el cual ven acechado por el feminismo.

Palabras clave: ideología de género, nueva derecha, feminismo, sexualidades, clases sociales

\footnotetext{
* Artículo recibido el 14/07/20 y aceptado el 19/10/20.

** Universidad Autónoma de Baja California-Instituto de Investigaciones Culturales-Museo. Avenida Reforma y Calle "L" s/n, col. Nueva, 21100 Mexicali, B.C. <areli.veloz@uabc.edu.mx>. orciD: https://orcid.org/0000-0002-3772-3267
} 


\section{Introducción}

L as movilizaciones políticas de los últimos años por la despenalización del aborto y por el reconocimiento de la diversidad sexual en América Latina han propiciado la exacerbación de discursos en contraposición que se manifiestan en el espacio público. Algunos grupos que comúnmente se adscriben a las Iglesias católica y evangélica han sido los más activos en defender y resguardar la noción tradicional de la familia desde la crítica a la (llamada por la derecha) ideología de género.

En el caso de México, en los últimos años se han generado tensiones entre distintas facciones políticas en torno a la participación e intervención de diversas instituciones religiosas, como la católica y la evangélica, en los debates sobre la agenda de género. Desde 2007, con la despenalización del aborto en la Ciudad de México, y el reconocimiento del matrimonio igualitario, en 2009, cobraron fuerza en varios estados del país grupos conservadores que reclamaban el derecho a la vida desde la concepción y a la familia tradicional, con el argumento de que existía una crisis de la familia y las identidades sexuales por las políticas que los gobiernos en turno estaban adoptando, lo cual relacionaban con el repunte de la violencia y las crisis económicas que habían abatido a la nación en los últimos tiempos. Dichas inconformidades se concretaron con las reformas a los códigos civil y penal de distintas constituciones estatales, entre ellas la del estado de Baja California, y que fueron impulsadas por los partidos de corte conservador: el Partido Acción Nacional (PAN) y el Partido Encuentro Social (PES).

Diferentes investigaciones sobre el conservadurismo en América Latina han señalado el reforzamiento entre la religión y la política en cuanto a los temas del género y/o la diversidad sexual. Estos estudios apuntan hacia un activismo desde las Iglesias -como la evangélica y la católica- que ponen en tensión el funcionamiento democrático (Vaggione, 2012 y 2017; Lemaitre, 2016; Cornejo-Valle y Pichardo, 2017; Miskolci y Campana, 2017; Bárcenas, 2018; López, 2018). Por otro lado, se ha planteado que el conservadurismo retomó a la educación como un ámbito central para enfrentar la agenda de género (Miguel, 2016; Lionço et al., 2018). La mayoría de estas investigaciones coincide en que hay una inconformidad del ala conservadora, que sintetiza en la ideología de género, provocada por movilizaciones por los derechos de las mujeres y los derechos de la diversidad sexual que aparecen desde finales del siglo $x x$.

Se tiene presente que actualmente existe un contexto más complejo que la mera oposición Estado
laico-Iglesia que permeó casi todo el siglo xx en México (De la Torre, 2019: 160), pero se coincide, con otros estudios, en que en los últimos años se ha reforzado el vínculo entre distintos grupos religiosos, de posturas conservadoras, y el Estado para enfrentar a la ideología de género, lo cual ha redefinido los contornos y los límites de la democracia en México. Por tanto, es necesario ahondar en los discursos que subyacen en dichos vínculos para interpretar a la ideología de género desde su referente político (Miguel, 2016; Rodríguez, 2017). Por ello, este artículo tiene como objetivo analizar las contiendas discursivas que se sintetizan en la llamada ideología de género desde las particularidades locales. Se considera que las particularidades son las que redefinen y otorgan coherencia a un conjunto de significados en torno a la defensa y la seguridad de un orden moral, el cual subyace en una visión creacionista del mundo, que es preservado por las elites locales, quienes ejercen un papel crucial en las acciones políticas de las localidades.

En Baja California, la derecha ha tenido una presencia significativa desde finales del siglo xx. Fue el primer estado en el país gobernado por un partido de tendencia conservadora, el PAN. Asimismo, en 2006 se fundó el PEs, bajo "agrupaciones neopentecostales, pero sin ser abiertamente un partido confesional" (Garma, 2019: 41). En la ciudad de Mexicali, cabecera municipal, y también capital del estado, se concentran los tres poderes de gobierno, por lo cual la presencia y la actuación de distintos grupos y asociaciones conservadores, como los provida o profamilia, se tornan más visibles $\mathrm{y}$ dinámicas, lo que ha fortalecido redes $\mathrm{y}$ alianzas entre diferentes asociaciones. Por último, en 1999, el caso Paulina -que mencionaré más adelantefue punto de atención en el plano nacional e internacional, en torno a las tensiones entre conservadores y progresistas al aludir al tema del aborto y del Estado laico, y fue un referente para las políticas sobre la despenalización del aborto en el nivel nacional.

Este texto pone en diálogo diversas reflexiones que surgen de los estudios culturales y de las descripciones etnográficas, los análisis de la literatura producida por los grupos conservadores sobre la ideología de género, las iniciativas de ley en torno a la despenalización del aborto y el matrimonio igualitario, y el seguimiento periodístico sobre las acciones que distintos grupos conservadores llevaban a cabo en el espacio público y en las redes sociales, como Facebook y Twitter, tanto en el ámbito local como en el nacional. Trabajo que se llevó a cabo entre 2018 y 2019.

Asimismo, se acudió a varias actividades -seminarios, talleres y manifestaciones en diferentes puntos de Mexicali- organizadas por grupos como el Frente 
Nacional por la Familia (FNF); salvemoslas2vidas; Frente Ciudadano en Defensa al Matrimonio "Solo Hombre y Mujer”; Iniciativa Ciudadana por la Vida y la Familia; Somos Pastoral de la Vida; Coalición para la Participación Social en la Educación, A.C., y 40 Días por la Vida. La mayoría de estas organizaciones trabajan en conjunto y/o son parte de las Iglesias católica y neopentecostales.

Se parte de un "método abierto de investigación" (Guber, 2015: 19), donde se emplearon distintas actividades con el objetivo de entrever cuáles son los discursos y las acciones que surgen de los grupos conservadores, los alcances de sus propuestas políticas, cómo se reproducen sus creencias, de qué manera se aprenden y difunden y en qué medida se redefinen para adquirir coherencia en contextos específicos.

Para sustentar el argumento propuesto, en un primer momento se mencionará cómo surge la ideología de género y su relación con una moralización de la política (Mouffe, 2011). Después se esbozará, de forma breve, la conformación de la nueva derecha en Baja California, identificando algunos momentos coyunturales para su despliegue político. Consecuentemente se referirán algunas actividades y estrategias que realizan los grupos conservadores en Mexicali, para conocer y aprender sobre la ideología de género y para crear alianzas y consolidarse en el plano local y transnacional. Por último, se analizarán los discursos que definen a la nueva derecha, los cuales moralizan la política por medio de una visión creacionista de la vida y estilos de vida en la ciudad.

\section{La ideología de género y la moralización de la política}

La definición de la ideología de género data de la década de los noventa, utilizada primero por la Iglesia católica y, posteriormente, por la evangélica (Machado, 2018; Miskolci y Campana, 2017). Dicho concepto, que contradice la teoría feminista y de la diversidad sexual, aparece en un momento fundamental para los feminismos, pues el concepto género se consolidó como una categoría analítica que rechazaba las concepciones biologicistas y binarias y le otorgó un papel central al referente cultural y político (De Lauretis, 1993; Scott, 1996).

Desde la Convención sobre la Eliminación de Todas las Formas de Discriminación contra la Mujer (CEDAw), promulgada en 1979, los sectores conservadores comenzaron a mostrar descontento por los derechos que las mujeres estaban conquistando en torno a la salud sexual y reproductiva. Después se crearon otros acuerdos internacionales ${ }^{1}$ que dieron cuenta de una creciente "ciudadanización de las mujeres" a partir de un mayor ejercicio, local y nacional, de la democracia (Maier, 2007: 186).

Sin embargo, desde la Reunión Preparatoria para la Cuarta Conferencia Mundial de la Mujer (celebrada en Beijing en 1995), se incorporó todo un andamiaje conceptual en torno a los derechos sexuales de hombres y mujeres, y no sólo los derechos humanos (Machado, 2018; Girard, 2007). Avance que representó el punto de inflexión para distintas facciones conservadoras, que se enfocaron en un discurso en contra de las políticas encaminadas a la equidad de género y los derechos sexuales y reproductivos. Desde el ala conservadora se enfatizaba el rechazo a la sustitución de la palabra "sexo" por "género", ya que desplazaba su concepción biológica a lo cultural, lo cual, adjudicaban, era impulsado por el feminismo (O'Leary, 2007; Ratzinger, 1997). Un feminismo que, consideraban, iba impregnándose en las agendas internacionales y nacionales y su trasfondo político era convertir al género en una ideología que promoviera el cuestionamiento a la estructura de la familia tradicional (Ratzinger y Amato, 2004; Consejo Episcopal Latinoamericano, 2007; Case, 2011).

En este sentido, la significación del género que es promovida por el feminismo, según se planteó desde diversos textos de orden religioso, es vista como una ideología (Machado, 2018: 4) que conceptualizan, siguiendo a Jorge Scala (uno de los principales teóricos conservadores en América Latina), como "un cuerpo de ideas cerrado, que parte de un presupuesto básico falso" (Zenit, 2012). Y, al mismo tiempo, lo equiparan con una guerra cultural, pues consideran que sus preceptos son impositivos, lo que produce polarización social.

La guerra cultural, de acuerdo con Nicolás Márquez y Agustín Laje -dos intelectuales de derecha en América Latina-, es un enfrentamiento por la definición dominante de la cultura, apareciendo como medio y como fin de la propia disputa (Márquez y Laje, 2016). O, según Scala: "el peligro de la ideología de género es muy sutil porque no busca imponerse por la fuerza de las armas, sino utilizando la propaganda para cambiar la mente y los corazones de los hombres" (Zenit, 2012).

1 Declaración de la Conferencia Internacional sobre Población y Desarrollo en El Cairo (1994 <https://www.un.org/en/ development/desa/population/publications/ICPD_programme_of_action_es.pdf>) y Convención Interamericana para Prevenir, Sancionar y Erradicar la Violencia contra la Mujer (Organización de los Estados Americanos, 1994 <http:// www.oas.org/juridico/spanish/tratados/a-61.html >). 
Desde la década de los noventa, el énfasis en la cultura, siguiendo a Fassin, fue central en la disputa política que desencadenó los cambios en torno al género y la sexualidad, aunque su trasfondo era la definición de la sociedad, lo que denominó "democracia sexual" (Fassin, 2015: 78). Las posturas de la Iglesia hacia los debates de la política sexual, según el autor, se justificaron bajo la premisa cultural, pero a principios del siglo xxi se sustituyó cultura por naturaleza, para enfatizar que la filiación era un elemento medular de la sociedad (Fassin, 2015: 79-80), lo que dio paso a un discurso "científico", desde el ala conservadora, para hacer frente a la ideología de género.

Dichos argumentos conformaron los contornos de la actuación política de las facciones conservadoras por medio de un creciente movimiento de orden transnacional, el cual se opone a los derechos sexuales y reproductivos. No obstante, aunque este movimiento

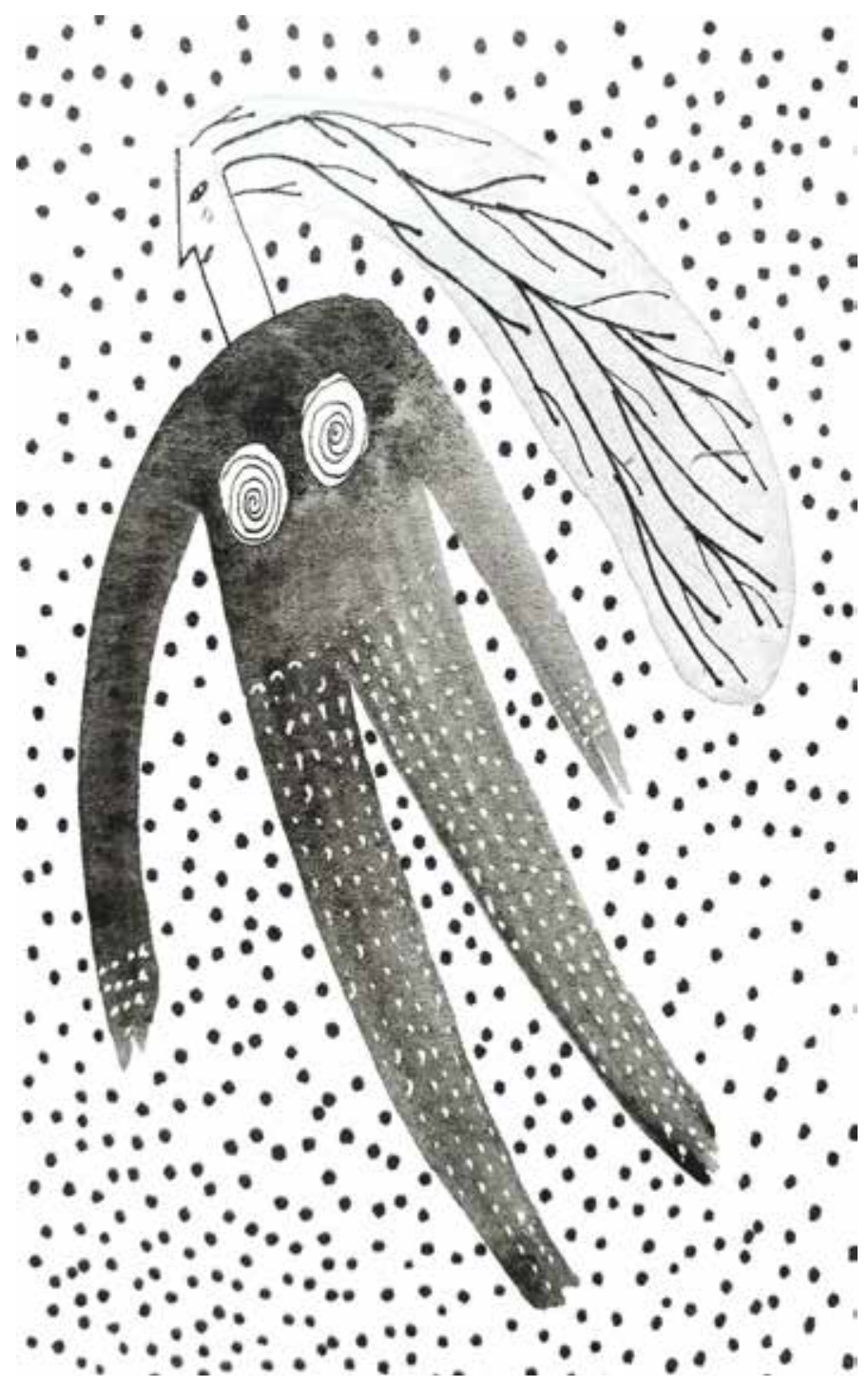

y su trasfondo discursivo son de carácter global, su organización y su fuerza política adquieren sentido en tanto los discursos que proclaman son redefinidos por los contextos y las particularidades locales, obteniendo un carácter localista donde las clases medias y altas tienen un papel preponderante.

La guerra cultural, a la cual hacen referencia, da cuenta de una disputa entre las elites "por las posiciones, los recursos y el capital simbólico que otorgue el poder" (Hunter cit. en Maier, 2015: 14). Disputa por los significados dominantes del género y las sexualidades, establecidos para y por una determinada elite, pero frente a los cambios de carácter subjetivo que los movimientos feministas trajeron consigo, entraron en tensión y en un aparente miedo a la pérdida de privilegios y poder. Por lo cual, bajo las contiendas discursivas alrededor de la familia, el matrimonio heterosexual y el aborto se encuentra una moralidad que prefigura un conjunto de significados en torno a la defensa y seguridad económica y social de una minoría privilegiada en un territorio específico.

El referente moral que subyace en los discursos seculares de las facciones conservadoras sigue cargando una visión creacionista para definir lo humano y, por ende, la vida. Discurso que se sustenta en la creencia de que el universo y la vida son consecuencia de la creación de un ser supremo o divino (Claramonte, 2013: 362), y el cual ha tenido sus propias disrupciones enmarcadas en la contienda sobre los significados de la vida y lo humano.

Por lo anterior, el término ideología de género se interpretará, en este artículo, desde la moralización de la política (Mouffe, 2011), la cual yace bajo una visión creacionista de la vida. Para Mouffe, la política democrática, de tendencia liberal, se ha enfocado en promover el consenso y la negociación de los conflictos sociales que aparecen en el terreno político, negando el reconocimiento del antagonismo como parte central de "lo político". Esta negación ha generado que, en la actualidad, se cree una oposición del nosotros/ellos que, en palabras de la autora, "se están formulando en términos de categorías morales" que hacen frente a una aparente "amenaza a la existencia" (Mouffe, 2011 : 83 y 23). Categorías que, agregaría, retoman y fortalecen binarismos que, ya sea por medio del argumento cultural o biológico, estratifican valorativamente el entendimiento de lo humano desde un discurso secular. Así, naturaleza/cultura, barbarie/civilización, reproducción/producción, femenino/masculino, vida/ muerte, entre otros, se van constituyendo como parte de un registro moral que legitima su contienda.

De tal suerte, en la guerra cultural, a la cual se refiere la nueva derecha, las principales instituciones 
sociales, como la familia y la educación, o los valores tradicionales en un determinado contexto, aparecen como elementos medulares que definen los contornos culturales y de la naturaleza humana que, ficticiamente, parecen estables y, por ende, son defendidos desde preceptos morales-que provienen de creencias religiosas-. En este sentido, además de retomar el vínculo entre Iglesia y Estado, es necesario reconocer las retóricas morales que hacen hincapié en dividir a un nosotros / ellos, lo cual termina excluyendo, desde "el bien y el mal”, a gran parte de la población.

\section{La defensa por la vida y la familia en las agendas políticas locales}

El Estado laico en México se ha construido desde mediados del siglo XIX, pero, aún ahora, es recurrente que distintos partidos políticos o funcionarios públicos acudan a las autoridades religiosas o utilicen un discurso religioso para buscar legitimidad política (Blancarte, 2008: 18). Dicha intromisión se ha facilitado por las reformas a la Constitución Política mexicana, en 1992, donde se establece una mayor presencia de las Iglesias en el espacio público. ${ }^{2}$ Aunque la separación de la política y la religión se siguió manteniendo, la presencia de las Iglesias, como la católica y la evangélica, es sumamente notoria, lo cual se compaginó con la entrada de un gobierno conservador, en el año 2000, representado por el PAN (Blancarte, 2008: 23) y, después, desde 2018, con el triunfo de un partido de izquierda -Movimiento de Regeneración Nacional (Morena)- (Garma, 2019: 43).

La intromisión de la Iglesia en los asuntos de Estado ha sido variada, pero entre lo más significativo está la disputa en torno a las políticas de género. En 2016 la llamada ideología de género se presentó como un proyecto integrador tras la propuesta al Poder Legislativo federal de una iniciativa de ley de reconocer el "matrimonio sin discriminación", la cual planteaba que en todas las entidades federativas podría llevarse a cabo el matrimonio entre personas del mismo sexo, sin embargo, fue rechazada. En 2017 se promovieron las reformas constitucionales de la Ciudad de México, donde se le reconocía como una "ciudad incluyente", destacando los temas de la familia, el matrimonio y la sexualidad. Dichos temas llevaron a que los sectores conservadores se expresaran en contra de la agenda de género por medio de la creación y el fortalecimiento de agrupaciones civiles.

En los últimos años, las asociaciones civiles abiertamente antigénero han consolidado sus demandas en las agendas políticas de las facciones conservadoras, representadas por partidos como el PAN y el PES. Por medio de alianzas entre organismos intermedios, como universidades, colegios, organismos empresariales, asociaciones civiles, etcétera, que forman parte del "tejido social donde la derecha política confluye con el sector conservador de la iglesia" (De la Torre, 2005: 250-251), se va fortaleciendo el proyecto político de la nueva derecha. Una nueva derecha que impulsa el resguardo de un orden moral, con tintes religiosos que, además, se funda en un contexto donde se manifiestan los malestares e inconformidades de grandes sectores de la población, por las crisis económicas y sociales de las últimas décadas, articuladas a las transformaciones de la institución de la familia y los roles tradicionales de género.

Las tensiones alrededor de la familia y los roles de género en el nivel nacional comienzan desde la década de los setenta, cuando aparecen las campañas de planificación familiar, impulsadas por el gobierno en turno, así como el fortalecimiento del movimiento feminista. En el caso de Baja California, los cambios que ocurrían en el plano nacional en torno a la familia, las sexualidades y las maternidades pusieron en tensión a los sectores conservadores, dando paso a la creación de políticas de moralización que tenían por objetivo salvaguardar a las ciudades fronterizas, como Tijuana y Mexicali, de los males que provenían del centro de México o del extranjero (como se decía en la prensa local en esos años). En ese contexto se debatía el rol tradicional de las mujeres y los significados dominantes de las sexualidades frente al auge del movimiento feminista que se generaba en los ámbitos internacional y nacional (Veloz, 2019).

Por otro lado, en dicho estado el PAn tuvo una fuerte presencia tras el descontento de las clases medias y altas por las crisis regionales. Algunos de sus dirigentes políticos provenían de organizaciones y movimientos religiosos que defendían los postulados tradicionales de la familia, pero desde un pensamiento católico y laico (Vicencio, 1999: 30). En 1989, por primera vez, tras más de 70 años de un partido único en el poder, el Partido Revolucionario Institucional (PRI), el PAN gobernó una entidad federativa.

2 Desde mediados del siglo xix se han registrado distintos conflictos entre conservadores y liberales, redefiniendo el carácter del Estado laico mexicano. Entre ellos, la promulgación de las Leyes de Reforma, en 1860, que fueron conformando al Estado laico. Posteriormente, con la Revolución mexicana, se dio una relación ríspida entre la Iglesia y el Estado, lo cua llevó al acuerdo de consolidar un Estado que preservara el espacio público, en el terreno sociopolítico, y mayores libertades, en el ámbito educativo, a las Iglesias (véanse Blancarte, 2008: 21-22 y Garma, 2019: 38-40). 
Un caso particular es la ciudad fronteriza de Mexicali, cabecera municipal de Baja California. En ella se concentran los tres poderes de gobierno, por lo cual la presencia y la actuación política de grupos como los provida y profamilia han sido sumamente visibles y significativos para la nueva derecha, ya que tienen como cometido una participación activa en el espacio público y la consolidación de sus redes con representantes políticos de las facciones más conservadoras de partidos como el PAN y, posteriormente, con el PEs.

En 1999, trascendió al plano nacional e internacional el caso Paulina, el cual puso en discusión el tema del aborto. Existen numerosos artículos (Grupo de Información en Reproducción Elegida, 2008) que refieren el suceso. ${ }^{3}$ Pero lo que aquí interesa resaltar es cómo se convirtió en una plataforma política para distintas figuras públicas en la entidad. El caso Paulina puso en la mesa de discusión, además de la violación a sus derechos, la intromisión de la Iglesia en los asuntos políticos de un Estado laico, y las alianzas entre funcionarios públicos y organizaciones civiles religiosas para debatir políticamente sobre la sexualidad y la reproducción.

Posterior al caso Paulina, en el nivel nacional, se hicieron distintas reformas y leyes ${ }^{4}$ en torno a la despenalización del aborto, concretamente en la Ciudad de México, impulsadas por diversos grupos feministas, así como por los partidos políticos de tendencias progresistas, representadas por el Partido de la Revolución Democrática (PRD). No obstante, el impulso de una agenda de género en las políticas públicas dio paso a una polarización política que, en el caso de las facciones conservadoras, consolidó un discurso sobre la ideología de género, al mismo tiempo que fueron apareciendo diferentes organizaciones civiles aliadas, o no, con coaliciones de grupos religiosos que estaban en contra de dichos temas tanto internacional como nacional y localmente.

Durante el actual gobierno federal, encabezado por Andrés Manuel López Obrador, la cuestión de la familia ha sido un referente de disputa. Para el presidente, la desintegración familiar es vista como un efecto del contexto neoliberal, por lo cual la familia debe ser restaurada, pues es una de las "instituciones de seguridad más importantes del país” (Barranco y Blancarte, 2019: 15). Así, mediante un discurso religioso, López Obrador ha puesto énfasis en una agenda moral que tiene el objetivo de reconstruir el tejido social y comunitario de la nación tras años de violencia y las crisis económicas y políticas que ha vivido. Promoción sustentada por la Dirección General de Asociaciones Religiosas y por grupos y asociaciones de distintas Iglesias -concretamente por medio de la Confraternidad Nacional de Iglesias Cristianas Evangélicas (Confraternice).

El panorama político actual, respecto a las propuestas del gobierno federal, como el proyecto de reconstrucción nacional y el impulso que le ha dado Morena a las iniciativas de ley en torno a la despenalización del aborto, el derecho al matrimonio igualitario y el cambio legal de la identidad de género, muestra contradicciones que recaen en los preceptos morales que recubren las políticas democráticas del país. En este sentido, lo moral recae en la significación de la familia, la vida y la reproducción, convirtiéndose en los principales blancos de la disputa y la polarización en las agendas políticas actuales.

En la ciudad de Mexicali, las organizaciones civiles tejen alianzas con las Iglesias católica y evangélica, con partidos políticos y funcionarios públicos, a la vez que inciden de manera importante en la localidad, $\mathrm{y}$ forman parte de redes nacionales y transnacionales provida y profamilia. Organizaciones que se autogestionan, a través de las Iglesias o de otros intermediarios, como los pequeños o medianos empresarios, o recurren a fondos internacionales o nacionales. Al mismo tiempo, tienen representación política en la Cámara de Diputados y en la de Senadores y, por tanto, promueven una agenda política que posibilitan la toma de decisiones desde sus preceptos morales (De la Torre, 2005: 250-251).

\section{Acciones y alianzas contra la ideología de género en la localidad}

Desde 2016, la ideología de género comenzó a hacerse visible en la agenda política de los grupos conservadores mexicalenses, aunque ya existían antecedentes sobre el malestar y el actuar político frente al tema. Sin embargo, es central mencionar cómo los discursos que dan cuenta de la ideología de género son redefinidos, mediante distintas estrategias, para promover un sentido de la realidad sustentada en preceptos morales.

Entre los elementos que redefinen a la nueva derecha están conocer, aprender y llevar a la práctica

\footnotetext{
3 Paulina, una niña de 13 años que quedó embarazada tras una violación, apeló, junto con su madre, por el derecho a la interrupción del embarazo, pero se presentaron irregularidades que impidieron realizarlo. Para más información véase Grupo de Información en Reproducción Elegida (2008).

4 Más información sobre las leyes y reformas puede verse en Lamas (2009).
} 
los postulados surgidos de la ideología de género. Para ello se organizan seminarios, conferencias y talleres donde se involucran diferentes organizaciones e Iglesias, impulsando el aprendizaje sobre los temas que giran en torno a la ideología de género, fomentando el debate y las propuestas políticas desde los intereses de la derecha. Después del caso Paulina, la Iglesia católica, junto con diversas organizaciones civiles, patrocinaron "marchas, misas, reuniones, rezos colectivos" (Maier, 2010: 22) y seminarios sobre los derechos humanos y la familia, temas constitutivos de su discurso, y explicaba de lo que trataban (Van Dijk, 2003: 59).

El FNF es una de las asociaciones con mayor participación política en Mexicali. Entre sus objetivos está "impulsar la Ciudadanía de la Familia” mediante el "involucramiento público de la familia, como derecho y deber" (Frente Nacional por la Familia, 2019). También incita a la creación de leyes que contrarresten la agenda de género por medio de políticas de familia, las cuales tienen como fin el rescate de la matriz heterosexual, sustentada en "los principios del diseño original” (Frente Nacional por la Familia, 2019).

En Mexicali, el FNF tiene el objetivo de consolidarse mediante la formación e incorporación de nuevos militantes. Para ello, se concentran diversas asociaciones de distintas religiones, quienes se apoyan para organizar, promover y realizar eventos donde se creen alianzas. En los encuentros participan universidades o escuelas de educación media superior, privadas, con prestigio en lo local, al mismo tiempo que, a través de ellas, se consolidan las redes de las clases medias y altas en la ciudad.

Algunas de las actividades que se han impulsado en la ciudad son los seminarios y talleres, donde se convoca a ideólogos de la derecha para que enseñen y adoctrinen a los miembros de distintos grupos, a la vez que ganan nuevos adeptos. Entre 2018 y 2019 participaron -entre otros- el politólogo Agustín Laje y el abogado Nicolás Márquez, ambos argentinos y conocidos por sus teorizaciones sobre la ideología de género y sus puntos de vista en contra del feminismo y de la izquierda. También participó la alguna vez "feminista" Sara Winter, activista provida, y coordinadora nacional de Políticas para la Maternidad en el gobierno de Jair Bolsonaro en Brasil. Estas personalidades, junto con conductores de televisión y psicólogos de reconocida posición conservadora en México, fueron protagonistas de los eventos realizados en las instalaciones de escuelas privadas y templos católicos, donde también estuvieron presentes líderes evangélicos, profesores y directivos de diversas escuelas.

Los seminarios y talleres que imparten se compaginan con la organización de manifestaciones. Para estos sectores es trascendental trasladar del espacio privado -las iglesias o los recintos evangélicos-al público sus postulados teóricos, a fin de hacer visibles sus posturas, ya que, como mencionan, es ahí donde ganan adeptos a través de un discurso secular, y se conectan con otras manifestaciones nacionales e internacionales.

Entre los eventos que destacan se encuentra el Movimiento Nacional en Defensa de la Vida (impulsado por el FNF), el cual se organiza cada año, y cuyo objetivo es impulsar la ciudadanía de la familia. En 2019 se realizó en Mexicali, y acudieron y participaron distintos frentes, coaliciones y asociaciones de todo Baja California. Asistieron alrededor de 2000 personas, sobresaliendo las Iglesias católica y evangélica, así como jóvenes y profesores de escuelas privadas. Cabe subrayar que gran parte de los asistentes a la marcha pertenecía a las clases medias y altas, lo cual se evidenciaba por los contingentes, entre ellos iglesias $\mathrm{y}$ colegios ubicados en zonas de alto nivel adquisitivo en la ciudad (notas de campo, 22 de septiembre de 2019).

Los postulados llevados a la práctica en las manifestaciones tienen por objeto mostrar a la población la imagen del buen ciudadano, aquel que resguarda la integridad de la familia mediante valores como el honor, el respeto y el prestigio. Por ello, con anterioridad a las manifestaciones se realizan sesiones en las cuales se establece un tipo de reglamento, donde se enfatiza evitar los rezos en público y, en su lugar, expresar un discurso de carácter secular que demande los derechos humanos universales expresados en consignas como "ideología no, biología sí" o "el primer derecho es el derecho a la vida”. Asimismo, se incita al buen comportamiento, para diferenciarse de las movilizaciones feministas o de la diversidad sexual, a quienes se les caracteriza de manera negativa, aludiendo que sus actos son violentos, sucios y vandálicos. Para estos grupos es central mostrar en el espacio público que no son individuos aislados en las Iglesias, sino ciudadanos íntegros que resguardan a la familia tradicional, por lo cual su derecho estriba en defenderla de los gobiernos adoctrinados con la ideología de género (notas de campo, 22 de septiembre de 2019).

El discurso que proclaman en estas manifestaciones es parte del malestar contra diversos representantes políticos, donde destacan los de Morena, quienes son señalados como enemigos por las iniciativas de ley que proponen -la despenalización del aborto, la educación sexual en las escuelas y la reforma al código civil en torno al matrimonio igualitario-. Si bien el gobierno actual ha planteado una mayor apertura hacia los preceptos religiosos dentro de su proyecto político, también ha promovido una agenda de género que causa 
malestar en distintos sectores de la población y que se refleja en manifestaciones como las organizadas por grupos provida y profamilia.

En resumen, las organizaciones y los grupos conservadores de la ciudad, en su mayoría pertenecientes a los sectores sociales medios y altos, crean estrategias e impulsan campañas mediante temas como la familia y los derechos humanos, que son abordados desde representaciones que recaen en el nosotros/otros, otorgando sentido a sus acciones y alianzas. Al mismo tiempo, tienen como objetivo ganar adeptos y reforzar sus cuadros políticos por medio de seminarios y talleres, impulsando un discurso secular que oculte la visión creacionista que ha ido moralizando la política.

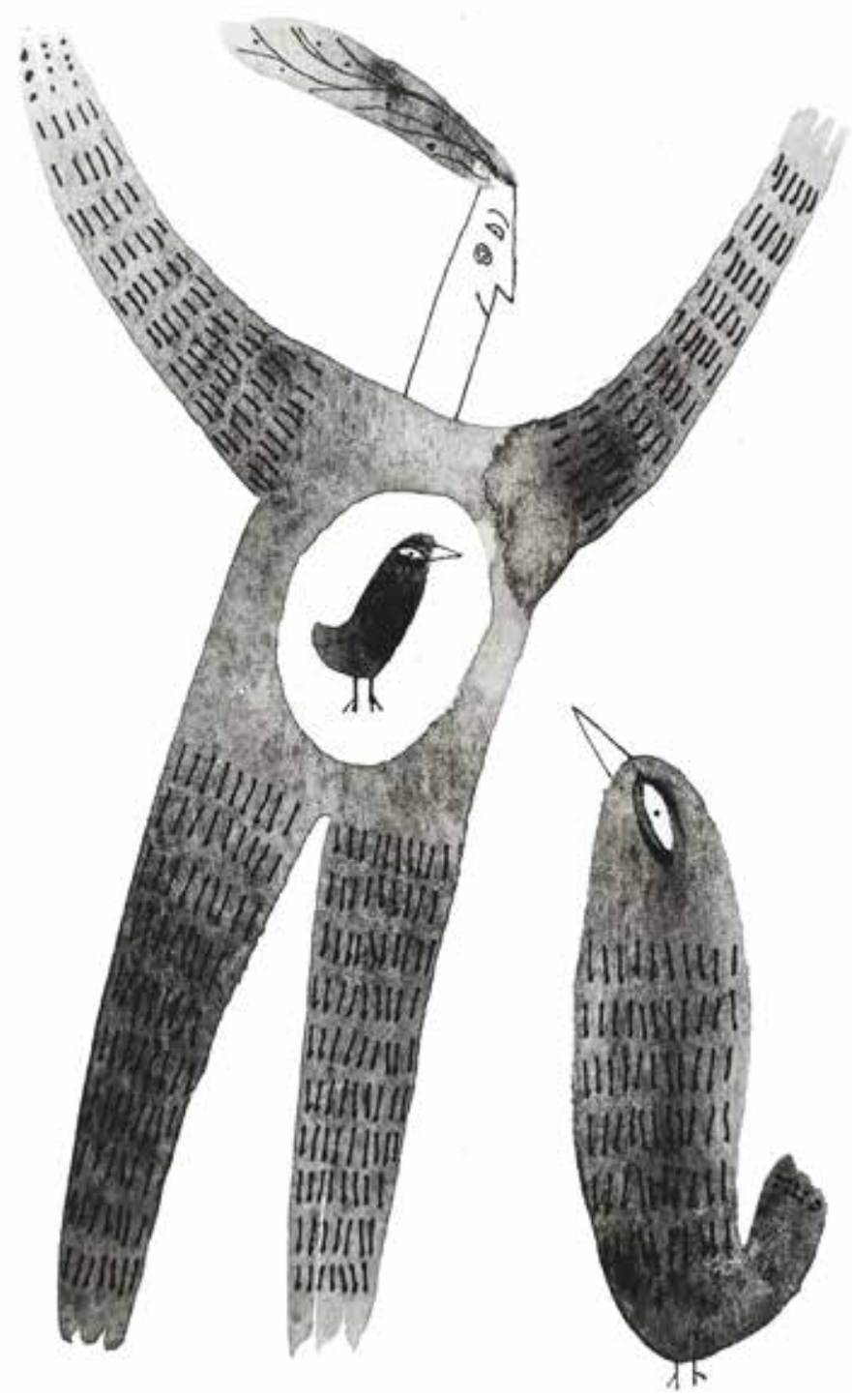

\section{El fortalecimiento de la nueva derecha y la moralización de la política}

En los seminarios y talleres que se organizan, además de referir a la ideología de género, como ya se mencionó, refuerzan la estrategia de ofrecer un discurso secular para tener presencia en lo público. Se destaca que el feminismo y los movimientos por la diversidad sexual han adoctrinado tanto a la sociedad civil como al Estado, lo cual, además de ir en contra de las posturas políticas del ala conservadora, desestabilizan y van en contrasentido de la naturaleza humana. Por ello, los discursos proclamados aluden a temas que se consideran relevantes para la existencia de grupos que comparten creencias similares, siendo el aborto y la vida parte medular de la contienda.

Entre marzo y abril de 2019 se realizó el simposio internacional "Derrumbando mentiras globales", en la Ciudad de México, Hermosillo (Sonora), Toluca (Estado de México) y Mexicali, cuyo propósito era contrarrestar las posturas feministas en torno al aborto mediante temas como la guerra cultural. En él participaron importantes personajes como Agustín Laje, Sara Winter y Chinda Brandolino. En Mexicali, el simposio tuvo alrededor de 600 o 700 asistentes, y entre los discursos destacaba mencionar que el feminismo es una ideología que mueve a las mujeres en masas para reclamar el derecho al aborto. Interpretan a las feministas como aquellas que quieren tener sexo libremente sin respetar el orden natural, por lo cual proponen que se plantee la doctrina del mal menor, ${ }^{5}$ donde las mujeres que apelan a su derecho a la libertad sexual sean consideradas no capacitadas para ser madres. Los expositores también sugieren la doctrina milenaria, ${ }^{6}$ que justifica que el niño tenga derecho por encima de la madre y el padre, idea contraria a lo que disponen las feministas en cuanto al derecho a decidir sobre su cuerpo. Argumentos que, sostienen, son fundamentales para derrumbar las mentiras que el feminismo ha divulgado y que ha impregnado al Estado (notas de campo, 30 de marzo de 2019).

En el caso de la guerra cultural, se ha convertido en parte de una argumentación que justifica la reprobación del aborto. En dicho simposio se planteaba que la guerra cultural es auspiciada por un nuevo orden mundial que justifica el negocio de las farmacéuticas transnacionales y las clínicas abortistas. Refieren a que existen organizaciones no gubernamentales multimillonarias, como Planned Parenthood, con intereses

\footnotetext{
5 Se debe procurar el bien en lo posible, lo que legitima el mal menor para evitar uno mayor.

6 Según la cual Cristo volverá a la tierra para reinarla por 1000 años.
} 
que "lucran con el aborto porque es un gran negocio". Indican que las fuerzas internacionales, a través de la Organización de las Naciones Unidas y la Organización de los Estados Americanos, imponen una ideología de género y "nuestros gobiernos se deben a agendas que no elegimos y ni siquiera conocemos". Señalan que los beneficios políticos están vinculados a los económicos y son las mujeres de los países pobres con quienes se lucra. La guerra cultural, consideran, se da en distintos niveles, y los foros internacionales son centrales para librar las batallas en torno a la ideología de género (notas de campo, 19 de septiembre de 2019).

La guerra cultural, según Agustín Laje, debe asumirse mediante un "discurso menos teológico y más filosófico” (Martínez y Burgueño, 2019: 52). Por tal razón, en seminarios contra el aborto impulsan a los asistentes a que se posicionen políticamente, no sólo desde la creencia religiosa, sino desde el discurso secular para enfrentar a una izquierda posmoderna que defiende y sustenta una ideología que opera en una geopolítica basada en las diferencias culturales (notas de campo, 19 de septiembre de 2019).

Su entendimiento sobre cultura es aquella que demarca las diferencias y los límites de una visión imaginaria del nosotros / otros, donde el otro, visto por los intelectuales de la derecha, tiene sus implicaciones políticas, ya que prefiguran un enemigo, como las feministas. Entre sus estrategias está el reafirmar una identidad nacionalista desde una visión creacionista, es decir, se continúa concibiendo el bien y el mal desde la barbarie y la civilización, y donde, como mencionó una de las conferencistas del simposio, el pensamiento feminista es significado desde el salvajismo, por sus demandas en torno al aborto o el cambio de sexo, ya que van en contra de la naturaleza humana (notas de campo, 30 de marzo de 2019).

Preconcepción cultural que puede reflejarse en un discurso políticamente correcto disimulado tras los principios de la ciencia, lo cual le otorga legitimidad a aquél. Así se observó con la conferencia del psicólogo Everardo Martínez, "especialista en el desarrollo de la heterosexualidad”, quien participó en el evento Vida y Familia, organizado por el FNF. El eje de su presentación fue la homosexualidad, y el psicólogo planteaba que es un trauma psicológico reversible y la heterosexualidad es desarrollable. En su exposición explicaba un discurso científico, sustentado en la tradición judeocristiana, que exalta la relación hombre/mujer desde la complementariedad, la cual se encuentra en los pasajes bíblicos (notas de campo, 25 de mayo de 2019).

El discurso del psicólogo se legitima a través de una visión judeocristiana que ha ido conformando y sustentando las representaciones sociales de creen- cias compartidas por un grupo, al mismo tiempo que funcionan como un marco de referencia que le da coherencia global a dichas creencias (Van Dijk, 2003: 24). Así, la normativa diferencial y complementaria entre hombres y mujeres y la reprobación de los feminismos por tratar de desestructurarla se expresa sin ambages en tales eventos. En la conferencia del psicólogo se hablaba del papel de la madre como cuidadora y responsable de desarrollar la heterosexualidad de los hijos. Para el expositor, existen dos tipos de relación con la madre que son perjudiciales para el desarrollo de la masculinidad de los hijos: la "mamá cercana emocionalmente" -la que siempre está con el hijo-y "la mamá autoridad". En este último caso referenció que son madres que desestabilizan la relación complementaria en el matrimonio. Planteó que el feminismo ha provocado que las madres entren en competencia con los padres, lo cual lleva a problemas de identidad en el núcleo familiar, pues los hijos no saben cómo manejar los roles que socialmente les corresponden. En la misma línea decía que las mujeres deben saberse frágiles y amorosas, ya que "el hombre debe saberse necesitado" frente "a un feminismo que niega a las mujeres ser amadas" (notas de campo, 25 de mayo de 2019).

Con relación a los roles de género, el discurso utilizado por el psicólogo, amén de estar sustentado en la seudociencia, hace hincapié en la-aparente- encomienda social de las mujeres de transmitir los valores culturales de la sociedad, entre ellos la heterosexualidad, la división sexual del trabajo y la procreación. En ellas recae la responsabilidad de reproducir, además de hijos, identidades de género, donde se subraye de manera enfática la reproducción de hombres que asuman una masculinidad tradicional. Tales discursos ponen el acento en la histórica contienda por el control del cuerpo de las mujeres y en su, aparente, encomienda sociobiológica.

En gran parte de los discursos planeados en los seminarios y talleres, se reprueba y se responsabiliza al feminismo de las tensiones y crisis que vive la familia $\mathrm{y}$, por ende, la nación. El punto es, coincidiendo con Valencia (2010: 187), el miedo que se tiene, desde el patriarcado, a "la desvirilización de la sociedad". Frente a ello, la obligación moral de los grupos conservadores es reeducar a las mujeres en sus roles tradicionales basándose en los esencialismos de las feminidades para continuar con la tarea, no sólo de reproducir a la población, sino a ciertas masculinidades que, consideran, están en riesgo.

El referente central de dichos discursos estriba en resguardar los preceptos morales que sustentan la reproducción y los estilos de vida que crean a la nación. 
Sin embargo, ¿qué vidas y formas de vida merecen ser reproducidas? y ¿quiénes dictan los preceptos morales, traducidos en políticas, que legitiman la valoración -desigual- de aquellos individuos reconocidos como ciudadanos por un Estado-laico en riesgo?

\section{Conclusiones}

La redefinición y la legitimación de los discursos en torno a la ideología de género por los grupos conservadores no ocurren de manera uniforme y unívoca, pese a que existan alianzas y acuerdos cuando se trata de hacer frente a las propuestas o aprobaciones de leyes alrededor de la familia, la sexualidad y el aborto, lo cual se explica por dos aspectos. Por un lado, se encuentran las particularidades locales que le otorgan dinamismo a las propuestas y las acciones que promueven para sus propias agendas. Por otro lado, entre los grupos conservadores existen diversos intereses con los gobiernos en turno, los cuales, en ocasiones, van en contrasentido. No obstante, pese a las diferencias, las alianzas son fundamentales para la consolidación de una nueva derecha, en su carácter transnacional.

Asimismo, los discursos en torno a la ideología de género se han ido matizando en los últimos años, debido a la centralidad que han adquirido en el debate público, lo cual puede verse en su propia transición política: pasar de los argumentos de carácter culturalista a los biologicistas, o de posturas conservadoras a ultraconservadoras. Estas transiciones y matices muestran la complejidad en que se despliegan las demandas, las cuales subyacen en binarismos que se pretenden reforzar, como la relación cultura/naturaleza o civilización/barbarie, por medio de un discurso creacionista presentado como científico.

Entre los objetivos centrales de los seminarios y los talleres sobre la ideología de género está moralizar el discurso político que, de manera ambigua, se presenta como secular en temas como la vida, la familia y la sexualidad y, entre sus metas, está domesticar y, por ende, controlar lo que se sale de la norma. Es decir, se controlan aquellos cuerpos otros que se asocian al feminismo o a los movimientos por la diversidad sexual, pues saben que desestructuran la familia tradicional, esencial para el mantenimiento de estilos de vida sustentados en simbolismos que legitiman valoraciones sociales desiguales.

Por otra parte, las manifestaciones y las movilizaciones que dichos grupos realizan reflejan lo aprendido en los seminarios y los talleres, pero en la práctica $\mathrm{y}$ frente a demandas concretas es que el discurso va tomando coherencia, ganando adeptos y redefiniendo los nuevos cuadros de la derecha. El punto crucial, y que aparece en tensión, son los significados de las feminidades y las masculinidades, así como las sexualidades, frente a los cambios de época, donde se resguardan dicotomías valorativas que reproducen el nosotros/otros, como cultura/naturaleza, hombre/ mujer, femenino/masculino, barbarie/civilización, etcétera, convirtiéndose en parte crucial de la disputa por la vida y la familia.

La visión biológica o científica que, desde los postulados teológicos, justifican el ímpetu del movimiento de la nueva derecha encuentran su punto de inflexión en la defensa y el resguardo del cuerpo de las mujeres y de la simbolización tradicional de las feminidades y las masculinidades frente al, supuesto, adoctrinamiento social con la ideología de género. El objetivo es participar en una guerra cultural cuya meta es cuidar y fortalecer al sistema patriarcal, el cual, consideran, está en riesgo frente a los feminismos y los movimientos por la diversidad sexual, mismos que hay que apaciguar desde lo local.

\section{Fuentes}

BÁRCENAS, KARINA

2018 "Pánico moral y de género en México y Brasil: rituales jurídicos y sociales de la política evangélica para deshabilitar los principios de un Estado laico”, en Religião e Sociedade, vol. 38, núm. 2, julio-diciembre, pp. 85-118<https: / / www.scielo.br/pdf/rs /v38n2/0100-8587rs-38-2-00085.pdf> [15 de noviembre de 2019].

BARRANCO, BERNARDO

Y ROBERTO BLANCARTE

2019 AMLO y la religión. El Estado laico bajo amenaza, Grijalbo, México.

Blancarte, Roberto J.

2008 Libertad religiosa, Estado laico y no discriminación, Consejo Nacional para Prevenir la Discriminación, México.

Case, Mary AnNe

2011 "After gender the destruction of man? The Vatican's nightmare vision of the 'Gender Agenda' for Law", en Chicago Unbound, 31 Pace Law Review, pp. 802-817.

Claramonte, Vicente

2013 "La evolución del creacionismo: del mito cosmogónico a la pseudociencia biológica", en $\mathrm{Fi}$ losofia e História da Biologia, vol. 8, núm. 2, pp. 361-379.

CONSEJO EPISCOPAL LATINOAMERICANO

2007 V Conferencia General del Episcopado Latinoamericano y del Caribe, Consejo Episcopal Latinoamericano, Aparecida, 13-31 de mayo.

Cornejo-Valle, Mónica

Y J. IGNACIO PICHARdo

2017 'La 'ideología de género' frente a los derechos sexuales y reproductivos. El escenario español”, en Cadernos Pagu, núm. 50 <https:// 
www.scielo.br/pdf/cpa/n50/1809-4449cpa-18094449201700500009.pdf> [ 10 de octubre de 2019].

De Lauretis, Teresa

1993 "Sujetos excéntricos: la teoría feminista y la conciencia histórica”, en María Cecilia Cangiano y Lindsay DuBois (comps.), De mujer a género. Teoría, interpretación y práctica feminista en las ciencias sociales, Centro Editor de América Latina, Buenos Aires, pp. 73-113.

DiJK, Teun A. van

2003 Ideología y discurso, Ariel Lingüística, Barcelona.

FASSIN, Éric

2015 "Matrimonio del mismo sexo, nación y raza: lógica y retórica política en Francia”, en $R e$ vista Interdisciplinaria de Estudios de Género, vol. 1, núm. 1, enero-junio, pp. 76-97 <https: / / estudiosdegenero.colmex.mx/index.php/ eg/article/view/18> [21 de marzo de 2020].

Frente Nacional por la Familia

2019 “Quiénes somos?”, en Frente Nacional por la Familia <http://frentenacional.mx/quienessomos / > [21 de enero de 2020].

Garma, Carlos

2019 "Religión y política en las elecciones del 2018. Evangélicos mexicanos y el Partido Encuentro Social”, en Alteridades, año 29, núm. 57. enero-junio, pp. 35-46 <https://alteridades. izt.uam. $\mathrm{mx} /$ index.php/Alte / article / view / 1079> [ 15 de noviembre de 2019].

GIRARD, FRANÇOISE

2007 "United Nations", en Richard Parker et al. (eds.), Sex Politics. Reports from the Front Lines, Sexuality Policy Watch, Río de Janeiro, pp. 311-358.

Grupo de Información en Reproducción Elegida

2008 Paulina, justicia por la vía internacional, Grupo de Información en Reproducción Elegida, México <https: / / gire.org.mx/wp-content/ uploads / 2016/07/PaulinaJusticia_TD6.pdf $>$ [ 10 de noviembre de 2019].

Guber, Rosana

2015 La etnografía: método, campo y reflexividad, Siglo xxI, Buenos Aires.

Lamas, Marta

2009 "La despenalización del aborto en México", en Nueva Sociedad, núm. 220, marzo-abril $<$ https: / / nuso.org/articulo/la-despenaliza cion-del-aborto-en-mexico/> [5 de marzo de 2020].

Lemaitre, Julieta

2016 "El sexo, las mujeres y el inicio de la vida humana en el constitucionalismo católico", en Rebecca Cook, Joanna N. Erdnam y Bernard M. Dickens (eds.), El aborto en el derecho trasnacional, Fondo de Cultura Económica/Centro de Investigación y Docencia Económicas, México, pp. 306-331.

Lionço, Tatiana, Ana Clara de Oliveira,

Felipe Mattiello y Amanda Machado Freire

2018 “'Ideologia de gênero': estratégia argumentativa que forja cientificidade para o fundamentalismo religioso", en Psicologia Política, vol. 18 , núm. 43 , septiembre-diciembre, pp. 599-621.

López, JaIro ANTONIO

2018 "Movilización y contramovilización frente a los derechos LGBTI. Respuestas conservadoras al reconocimiento de los derechos humanos", en Estudios Sociológicos, vol. 36, núm. 106, enero-abril, pp. 161-187<https://estudios sociologicos.colmex.mx/index.php/es / article/view/1576> [ 17 de enero de 2020].

Machado, Maria das Dores Campos

2018 "O discurso cristão sobre a 'ideologia de gênero", en Revista Estudos Feministas, vol. 26, núm. 2, mayo-agosto <https://www. scielo.br/pdf/ref/v26n2 / 1806-9584-ref-2602-e47463.pdf> [ 12 de octubre de 2019].

Maier, Elizabeth

2007 "Convenios internacionales y equidad de género: un análisis de los compromisos adquiridos por México", en Papeles de Población, vol. 13, núm. 53, julio-septiembre, pp. 175202 <http://www.scielo.org.mx/scielo.php? script $=$ sci_arttext $\&$ pid $=$ S $1405-74252007$ 000300008> [20 de junio de 2020].

Maier, Elizabeth

2010 "El aborto y la disputa cultural contemporánea en México", en La Aljaba, segunda época, vol. XIV, pp. 11-30 <http://www. biblioteca.unlpam.edu.ar/pubpdf/aljaba / v14a01maier.pdf> [ 15 de marzo de 2020].

Maier, Elizabeth

2015 "La disputa sobre el aborto en México: Discursos contrastados de personificación, derechos, la familia y el Estado", en Revista Gerencia y Políticas de Salud, vol. 14, núm. 29, julio-diciembre, pp. 10-24 <https://www. redalyc.org/pdf/545/54543012001.pdf> [ 13 de marzo de 2020].

Márguez, Nicolás y Agustín LAJE

2016 El libro negro de la nueva izquierda: ideología de género o subversión cultural, Grupo Unión, Buenos Aires.

Martínez, Josefina L. y Cynthia Luz Burgueño

2019 Patriarcado y capitalismo. Feminismo, clase y diversidad, Ediciones Akal, Madrid.

Miguel, Luis Felipe

2016 "Da 'doutrinação marxista' à 'ideologia de gênero' - Escola Sem Partido e as leis da mordaça no parlamento brasileiro", en Revista Direito e Práxis, vol. 7, núm. 15, julio-septiembre, pp. 590-621 <https://www.e-publicacoes.uerj. br/index.php/revistaceaju / article / view / 25163/18213> [ 10 de noviembre de 2019].

Miskolci, RichaRd y MAXimiliano CAMPANA

2017 “Ideologia de gênero': notas para a genealogia de um pânico moral contemporâneo", en Revista Sociedade e Estado, vol. 32, núm. 3, septiembre-diciembre, pp. 725-747<https: / / www.scielo.br/pdf/se/v32n3/0102-6992se-32-03-725.pdf> [28 de enero de 2019].

Mouffe, Chantal

2011 En torno a lo político, Fondo de Cultura Económica, Buenos Aires.

O'Leary, DALE

2007 La agenda de género, Promesa, San José, Costa Rica.

RATZINGER, JosePH

1997 La sal de la tierra: cristianismo e Iglesia católica ante el nuevo milenio, Palabra, Madrid.

Ratzinger, Joseph y Angelo Amato

2004 "Carta a los obispos de la Iglesia católica sobre la colaboración del hombre y la mujer en la Iglesia y el Mundo", en vatican.va <https://www.vatican.va/roman_curia/ 
congregations / cfaith / documents / rc_con cfaith doc 20040731 collaboration sp. $\bar{h}$ tml $>$ [ 15 de enero de 2019].

Rodríguez, Manuel Alejandro

2017 "La ideología de género como exceso: Pánico moral y decisión ética en la política colombiana”, en Sexualidad, Salud y Sociedad. Revista Latinoamericana, núm. 27, diciembre, pp. 128-148 <https://www.scielo.br/pdf/sess/ n27/1984-6487-sess-27-128.pdf> [15 de di-

ScOtT, JOAN ciembre de 2019].

1996 "El género: Una categoría útil para el análisis histórico", en Marta Lamas (comp.), El género: la construcción cultural de la diferencia sexual, Programa Universitario de Estudios de Género, México, pp. 265-302.

ToRre, Renée DE LA

2005 "El catolicismo y las concepciones sobre el derecho a la vida”, en Renée de la Torre, Marta Eugenia García Ugarte y Juan Manuel Ramírez Sáiz (comps.), Los rostros del conservadurismo mexicano, Centro de Investigaciones y Estudios Superiores en Antropología Social/ Universidad Nacional Autónoma de MéxicoInstituto de Investigaciones Sociales, México, pp. 239-268.

TORRE, RENÉE DE LA

2019 "Alianzas interreligiosas que retan la laicidad en México", en Revista Rupturas, vol. 9, núm. 1, enero-junio, pp. 155-178<https: / / revistas. uned.ac.cr/index.php/rupturas/article/ view/2233> [3 de marzo de 2020].
VAGgione, Juan Marco

2012 "La 'cultura de la vida'. Desplazamientos estratégicos del activismo católico conservador frente a los derechos sexuales y reproductivos”, en Religião e Sociedade, vol. 32, núm. 2 , julio-diciembre, pp. 57-80 <https://www. scielo.br/pdf/rs/v32n2/04.pdf> [3 de noviembre de 2019].

VAGgione, JuAn MARCo

2017 "La Iglesia Católica frente a la política sexual: la configuración de una ciudadanía religiosa", en Cadernos Pagu, núm. 50 <https://www. scielo.br/pdf/cpa/n50/1809-4449-cpa18094449201700500002.pdf> [12 de enero de 2020].

VALENCIA, SAYAK

2010 Capitalismo gore, Melusina, Barcelona.

Veloz, AReli

2019 Las retóricas de la moralidad en la frontera. Análisis histórico de la sexualidad en Tijuana, Consejo Nacional para la Cultura y las Artes, México.

VICENCIO, TANIA

1999 "Estructura partidaria y movilidad política en el PAN de Baja California, 1986-1998”, en Revista Mexicana de Sociología, vol. 3, núm. 61, pp. 25-52.

ZENIT

2012 "Ideología de género como herramienta de poder. Entrevista con Jorge Scala", en Zenit, 1ㅇ de febrero <https://es.zenit.org/2012/02/01/ ideologia-de-genero-como-herramientade-poder/> [20 de febrero de 2020]. 